\title{
Continuous positive airway pressure setups evaluated at simulated exercise conditions
}

\author{
Marcelo Vieira Leão Nunes*, Antonio Giannella-Neto, Frederico Caetano Jandre de Assis Tavares
}

\begin{abstract}
Introduction: Studies have shown increases in airway opening pressure $\left(\mathrm{P}_{\mathrm{ao}}\right)$ swings and work of breathing (WOB) by different continuous positive airway pressure (CPAP) devices at rest, but few address this issue during exercise. The aim of the present work was to analyze the imposed WOB (WOBi), the apparent resistance (Rapp) and swings of $\mathrm{P}_{\text {ao }}$ (deltaP) of 3 CPAP assemblies at simulated exercise conditions. Methods: The CPAP measures were obtained from: a commercial CPAP (Assembly 1), a high flow CPAP (Assembly 2) and the parallel association of these devices (Assembly 3 ). In each assembly the spring-loaded positive endexpiratory pressure (PEEP) valve was set to fully opened (mode A) or at the same CPAP pressure (mode B). The exercise protocol simulation, performed manually by a calibrated syringe and a metronome, employed a respiratory frequency of $30 \mathrm{bpm}$, tidal volume of $2.7 \mathrm{~L}$ and inspiratory-to-expiratory ratio of 1 . The setups were evaluated at CPAP settings of 5, 10 and $15 \mathrm{cmH}_{2} \mathrm{O}$. Results: The lowest deltaP as well as Rapp and WOBi were obtained with Assembly 3 in mode A with an adjusted CPAP of $10 \mathrm{cmH}_{2} \mathrm{O}$ (deltaP=8.1 (0.5) $\mathrm{cmH}_{2} \mathrm{O}_{\text {, }}$ $\mathrm{WOBi}=1.4(0.14) \mathrm{cmH}_{2} \mathrm{O} / \mathrm{L} / \mathrm{s}, \mathrm{Rapp}=1.3(0.07) \mathrm{J} / \mathrm{s}$ ) showed as median (interquartile range). Conclusion: For the conditions studied, the best CPAP setup was obtained with mode A.
\end{abstract}

Keywords CPAP, Exercise, Imposed work of breathing, PEEP valve.

\section{Introduction}

The Continuous Positive Airway Pressure (CPAP) is a ventilatory intervention employed in exercise rehabilitation for patients suffering from chronic obstructive pulmonary diseases or congestive heart failure, as a tool to unload the respiratory muscles and consequently leading to a reduced physiological work of breathing (WOB) (Ambrosino and Strambi, 2004; Keilty et al., 1994; Wittmer et al., 2006).

Among the benefits ascribed to CPAP are the improvement in oxygenation, the reduction in WOB and also the reduction in left ventricular preload and afterload (Wittmer et al., 2006). Nevertheless, the reduction of WOB decreases as the CPAP swings increase (Gherini et al., 1979).

In theory, during a CPAP intervention, the airway opening pressure $\left(\mathrm{P}_{\mathrm{ao}}\right)$ should be kept constant throughout the entire respiratory cycle. However, in practice, usually the $\mathrm{P}_{\mathrm{ao}}$ decreases during inspiration and increases during expiration, due to the impedance of the device and respiratory circuits (Gherini et al., 1979; Katz et al., 1985). Thus, despite the CPAP intervention may decrease the physiological WOB, it imposes an additional work of breathing (WOBi) spent by the patient to overcome this impedance (Banner et al., 1996). Previous studies have shown that, at rest, $P_{a 0}$ swings and WOB depends on the device employed

*e-mail: m.v.l.nunes@ig.com.br

Received: 13 August 2013 / Accepted: 10 March 2014
(Gherini et al., 1979; Katz et al., 1985; Louis et al., 2010). However, few works addressed this issue at exercise conditions.

The aim of the this work is to analyze the load imposed by 3 CPAP assemblies, represented by the WOBi, Rapp and the swings of $\mathrm{P}_{\text {a }}$ (deltaP), during exercise simulations.

\section{Methods}

The 3 assemblies evaluated for the generation of CPAP comprise a commercial CPAP device, RemRest C1001 (Medical Industries America Inc., USA), named Assembly 1; a high-flow device, Oxy-PEEP (Comercial Médica, Brazil), named Assembly 2; and the third, the parallel association of the aforementioned devices, through a y-piece, named Assembly 3. The Oxy-PEEP device has a dial to adjust the inspired fraction of $\mathrm{O}_{2}\left(\mathrm{FiO}_{2}\right)$, which was kept at $95 \%$ throughout the experiments.

Figure 1 depicts the experimental setup. Each CPAP device was plugged into a limb of a t-type connector. A spring-loaded positive end-expiratory pressure (PEEP) valve (Vital Signs, USA) was connected to the other limb. The orthogonal way of the t-type connector was connected to a pneumotachograph (PTC) Fleisch \#3 

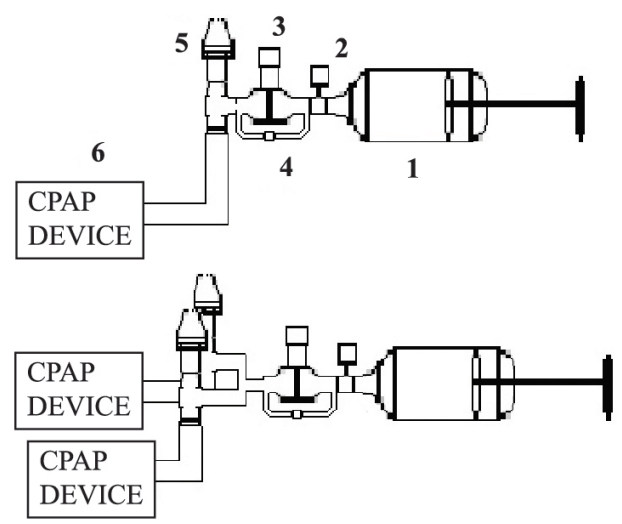

Figure 1. Diagrams representing the assemblies used to evaluate the CPAP systems. Upper: single device setup. Bottom: parallel association. 1: syringe; $2: \mathrm{P}_{\mathrm{a}}$ pressure transducer attached to a mouthpiece; 3 : flow rate pressure transducer attached to a pneumotachograph; 4 : bypass circuit with mainstream capnograph attached; 5: Spring-loaded PEEP valve; 6: CPAP device.

attached to a mouthpiece, which was connected to a calibrated syringe adjusted to a stroke volume of $2.7 \mathrm{~L}$. A bypass circuit, parallel to the pneumotachograph and intended for in vivo capnometry (not performed in the present work), was also present.

The flow rate $(\dot{V})$ was measured by a differential pressure transducer 176PC07HD2 (Honeywell, USA) with an operating range of $\pm 2 \mathrm{cmH}_{2} \mathrm{O}$, connected to the PTC. The $\mathrm{P}_{\mathrm{ao}}$ was measured with a pressure transducer, model 163PC01B48 (Honeywell, USA, range of -20 to $120 \mathrm{cmH}_{2} \mathrm{O}$ ). These signals were amplified and filtered by a low-pass, $4^{\text {th }}$ order analog Butterworth filter with cutoff frequency of $33 \mathrm{~Hz}$ by a purpose-built respiratory mechanics module, assembled in the lab especially for research in respiratory mechanics (Pino et al., 2004b). An analog-to-digital data acquisition board USB-6008 (National Instruments, USA), installed on a personal computer, acquired the signals at a sampling rate of $200 \mathrm{~Hz}$ through the software DAS (Pino et al., 2004a) running in LabView ${ }^{\circledR} 7.1$ (National Instruments, USA).

The flow rate was calibrated according to the technique described by Giannella-Neto et al. (1998), and the $\mathrm{P}_{a 0}$ was calibrated against a reference manometer RT-200 (Timeter Instrument, USA). In all cases, the baselines of the signals were measured prior to the experiments and were subtracted from the signals during off-line processing.

The CPAP pressures were previously adjusted at zero flow. For Assembly 3, the pressure generated by each device was set independently, also at zero flow. The spring-loaded PEEP valve was employed in either of two modes: fully opened (Mode A) or adjusted through its built-in dial to the same pressure of the CPAP (Mode B).
The breathing simulation protocol consisted in applying, for each of the 6 combinations of assemblies and modes, a respiratory rate of $30 \mathrm{bpm}$ (respiratory period (RP) of $2.0 \mathrm{~s}$ ), representing the upper bound expected during exercise (Haverkamp et al., 2005), at an inspiratory-to-expiratory time ratio (TI:TE) of 1. Experimental runs were performed at CPAP pressures of 5, 10 and $15 \mathrm{cmH}_{2} \mathrm{O}$. In each run, 3 trials comprising 30 breathing cycles were performed and the one showing the least mean squared error in tidal volume was chosen for analysis. The breathing cycles were performed without pauses between semi-cycles (inspirations and expirations). The first and the last respiratory cycles of each trial were excluded to avoid artifacts due to cycle detection. The experiments were performed at the sea level, room temperature of about $22{ }^{\circ} \mathrm{C}$.

The signals were processed with routines written

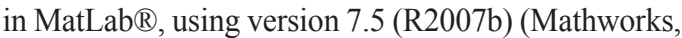
USA). In brief, the beginnings of inspirations and expirations were identified by zero-crossing of the flow signal. The volume was computed by numerical integration of the flow rate. The deltaP for each cycle was calculated as the difference between the mean expiratory $\mathrm{P}_{\mathrm{ao}}$ and the mean inspiratory $\mathrm{P}_{\text {ao }}$ :

$\operatorname{deltaP}_{(k)}=\frac{\left(\int_{I_{\text {exp }}(k)}^{I_{\text {ins }}(k+1)} P_{a o}(t) d t\right)}{T E}-\frac{\left(\begin{array}{l}I_{\text {exp }}(k) \\ I_{\text {ins }}(k)\end{array} P_{a o}(t) d t\right)}{T I}$

where:

$T I=I_{\exp }(k)-I_{\text {ins }}(k)$

$T E=I_{\text {ins }}(k+1)-I_{\text {exp }}(k)$

and $\mathrm{I}_{\text {ins }}(\mathrm{k})$ and $\mathrm{I}_{\text {exp }}(\mathrm{k})$ are the instants of the beginning $\mathrm{k}$-th inspiration and expiration, respectively. TI and TE are the inspiratory and expiratory periods, respectively.

The WOBi was obtained as:

$W O B i(k)=\int P_{a o}(t) \cdot \dot{V}(t) d t$

A further parameter, the apparent resistance (Rapp), is proposed in this study as an alternative figure of performance to evaluate the load imposed by the CPAP setup. The Rapp was estimated as the work of breathing divided by the numerical integral of flow squared:

$\operatorname{Rapp}(k)=\frac{\int P_{a o}(t) \cdot \dot{V}(t) d t}{\int \dot{V}(t) \cdot \dot{V}(t) d t}$

The inspiratory resistance $\left(\mathrm{R}_{\text {ins }}\right)$ and expiratory resistance $\left(R_{\text {exp }}\right)$ were separately calculated as in equations 6 and 7 : 


$$
\begin{aligned}
& R_{\text {ins }}(k)=\frac{\int\left(P_{a o}(t)-P_{a d j u s t}\right) \cdot \dot{V}(t) d t}{\int \dot{V}(t) \cdot \dot{V}(t) d t} \\
& R_{\exp }(k)=\frac{\int\left(P_{a o}(t)-P_{a d j u s t}\right) \cdot \dot{V}(t) d t}{\int \dot{V}(t) \cdot \dot{V}(t) d t}
\end{aligned}
$$

where:

$$
P_{\text {adjust }}=\frac{\int_{\text {end }}^{I_{\text {end }}-200} P_{a o}(t) d t}{200}
$$

and where $\mathrm{I}_{\text {end }}$ is the time corresponding the end of the signal and $I_{\text {end-200 }}$ is the time corresponding to one second before the end of the signal during zero flow signal. In the cases of $\mathrm{R}_{\text {ins }}$ and $\mathrm{R}_{\text {exp }}$, the formulae include $\mathrm{P}_{\text {adjust }}$, which represents the adjusted CPAP pressure and has to be subtracted in the semi-cycle so as to account only for the variations of the pressure due to flow.

All integrals were calculated numerically with the trapezoidal method.

\section{Statistical Analysis}

In all statistical tests, the figures of performance Rapp, WOBi and deltaP were analyzed to evaluate the null hypothesis of equal values. The KolmogorovSmirnov test showed that the figures of performance did not belong to a normal distribution. They are thus expressed as median (interquartile range), and the medians were employed in the non-parametric statistical tests, where applicable. The median values of the figures of performance were compared by the non-parametric one-way analysis of variance (KruskalWallis test) followed by the post-hoc Dunn's test. Mann-Whitney tests compared Mode A with Mode B at the same pressure and assembly. For each trial, the figures of performance from the cycles in which $\mathrm{V}_{\mathrm{T}}$, TI or TE were more than 1.5 times the interquartile range distant from the median were excluded from the statistical analysis. The trials are identified according to the assembly, mode and CPAP pressure, e.g. T1B05 meaning the trials performed with Assembly 1, mode $\mathrm{B}$ and CPAP of $5 \mathrm{cmH}_{2} \mathrm{O}$.

\section{Results}

Tables 1 and 2 shows the figures of performance for the trial selected for each test. Considering all groups, the $\mathrm{V}_{\mathrm{T}}$ error and the RP deviation were less than $\pm 2 \%$.

Tables 3 and 4 show the figures of performance estimated for each device. The highest deltaP was obtained in trial T1B10 $\left(\right.$ deltaP $\left.=17.4\left(1.5 \mathrm{cmH}_{2} \mathrm{O}\right)\right)$ and the lowest in the trial T3A10 (deltaP $\left.=8.1(0.5) \mathrm{cmH}_{2} \mathrm{O}\right)$, for which the WOBi as well as the Rapp were also the least.

The statistical analysis suggested the rejection of the null hypothesis of comparison among the 3 Assemblies for each pressure selected to the same mode, as well as of comparison among the 3 pressures for the same assembly in the same mode $(\mathrm{p}<0.001)$ for all figures of performance analyzed (deltaP, WOBi, and Rapp). However, the Dunn's test did not show statistical differences between trials T1A15 and T2A15. Mode A presented better performance than

\begin{tabular}{|c|c|c|c|c|c|c|c|c|c|}
\hline \multirow{2}{*}{$\begin{array}{l}\text { CPAP } \\
\text { Device }\end{array}$} & \multicolumn{3}{|c|}{$5 \mathrm{cmH}_{2} \mathrm{O}$} & \multicolumn{3}{|c|}{$10 \mathrm{cmH}_{2} \mathrm{O}$} & \multicolumn{3}{|c|}{$15 \mathrm{cmH}_{2} \mathrm{O}$} \\
\hline & 1 & 2 & 3 & 1 & 2 & 3 & 1 & 2 & 3 \\
\hline $\begin{array}{l}\text { Inspiratory } \\
\text { volume (1) }\end{array}$ & $2.66(0.01)$ & $2.69(0.02)$ & $2.64(0.01)$ & $2.68(0.02)$ & $2.67(0.02)$ & $2.68(0.02)$ & $2.70(0.02)$ & $2.67(0.02)$ & $2.69(0.02)$ \\
\hline $\begin{array}{l}\text { Expiratory } \\
\text { volume (1) }\end{array}$ & $2.68(0.02)$ & $2.71(0.01)$ & $2.66(0.01)$ & $2.71(0.02)$ & $2.69(0.01)$ & $2.70(0.02)$ & $2.71(0.03)$ & $2.69(0.01)$ & $2.70(0.01)$ \\
\hline TI (s) & $1.08(0.07)$ & $1.00(0.05)$ & $1.05(0.04)$ & $1.02(0.09)$ & $1.00(0.03)$ & $1.07(0.08)$ & $1.02(0.06)$ & $1.07(0.09)$ & $1.01(0.08)$ \\
\hline $\mathrm{TE}(\mathrm{s})$ & $0.93(0.04)$ & $1.01(0.04)$ & $0.95(0.03)$ & $0.98(0.10)$ & $1.00(0.07)$ & $0.95(0.04)$ & $0.96(0.07)$ & $0.93(0.06)$ & $0.97(0.09)$ \\
\hline
\end{tabular}
Mode B, with statistically significant differences

Table 1. Median and interquatile range of the figures of performance obtained from the trials with PEEP-valve fully opened.

\begin{tabular}{|c|c|c|c|c|c|c|c|c|c|}
\hline \multirow{2}{*}{$\begin{array}{l}\text { CPAP } \\
\text { Device }\end{array}$} & \multicolumn{3}{|c|}{$5 \mathrm{cmH}_{2} \mathrm{O}$} & \multicolumn{3}{|c|}{$10 \mathrm{cmH}_{2} \mathrm{O}$} & \multicolumn{3}{|c|}{$15 \mathrm{cmH}_{2} \mathrm{O}$} \\
\hline & 1 & 2 & 3 & 1 & 2 & 3 & 1 & 2 & 3 \\
\hline $\begin{array}{l}\text { Inspiratory } \\
\text { volume (1) }\end{array}$ & $2.64(0.02)$ & $2.65(0.03)$ & $2.67(0.02)$ & $2.67(0.02)$ & $2.69(0.04)$ & $2.71(0.02)$ & $2.66(0.01)$ & $2.69(0.02)$ & $2.66(0.02)$ \\
\hline $\begin{array}{l}\text { Expiratory } \\
\text { volume (1) }\end{array}$ & $2.66(0.02)$ & $2.67(0.03)$ & $2.69(0.02)$ & $2.69(0.02)$ & $2.70(0.04)$ & $2.72(0.02)$ & $2.68(0.01)$ & $2.70(0.03)$ & $2.68(0.02)$ \\
\hline TI (s) & $1.07(0.04)$ & $0.99(0.03)$ & $0.99(0.06)$ & $1.08(0.10)$ & $1.03(0.08)$ & $1.03(0.07)$ & $1.10(0.05)$ & $1.02(0.07)$ & $1.06(0.11)$ \\
\hline TE (s) & $0.94(0.02)$ & $1.02(0.05)$ & $1.00(0.04)$ & $0.91(0.07)$ & $0.97(0.08)$ & $0.99(0.04)$ & $0.90(0.01)$ & $0.96(0.08)$ & $0.92(0.06)$ \\
\hline
\end{tabular}

Table 2. Median and interquatile range of the figures of performance obtained from the trials with PEEP-valve set as the same value of CPAP pressure. 
Table 3. Median and interquatile range of the figures of performance evaluated with the PEEP-valve fully opened.

\begin{tabular}{|c|c|c|c|c|c|c|c|c|c|}
\hline \multirow{2}{*}{$\begin{array}{l}\text { CPAP } \\
\text { Device }\end{array}$} & \multicolumn{3}{|c|}{$5 \mathrm{cmH}_{2} \mathrm{O}$} & \multicolumn{3}{|c|}{$10 \mathrm{cmH}_{2} \mathrm{O}$} & \multicolumn{3}{|c|}{$15 \mathrm{cmH}_{2} \mathrm{O}$} \\
\hline & 1 & 2 & 3 & 1 & 2 & 3 & 1 & 2 & 3 \\
\hline $\begin{array}{l}\text { deltaP } \\
\left(\mathrm{cmH}_{2} \mathrm{O}\right)\end{array}$ & $13.9(1.4)$ & $9.6(0.7)$ & $8.3(0.3)$ & $12.8(1.4)$ & $10.5(0.6)$ & $8.1(0.5)$ & $13.6(1.5)$ & $13.3(0.8)$ & $10.1(0.6)$ \\
\hline $\begin{array}{l}\text { WOBi } \\
(\mathrm{J} / \mathrm{s})\end{array}$ & $2.4(0.26)$ & $1.7(0.13)$ & $1.5(0.09)$ & $2.1(0.23)$ & $1.8(0.15)$ & $1.4(0.14)$ & $2.3(0.20)$ & $2.3(0.18)$ & $1.6(0.11)$ \\
\hline $\begin{array}{l}\text { Rapp } \\
\left(\mathrm{cmH}_{2} \mathrm{O} / 1 / \mathrm{s}\right)\end{array}$ & $2.6(0.19)$ & $1.7(0.09)$ & $1.5(0.07)$ & $2.1(0.25)$ & $1.8(0.11)$ & $1.3(0.07)$ & $2.3(0.12)$ & $2.2(0.11)$ & $1.6(0.05)$ \\
\hline
\end{tabular}

Table 4. Median and interquatile range of the figures of performance evaluated with the PEEP-valve set as the same value of CPAP pressure.

\begin{tabular}{|c|c|c|c|c|c|c|c|c|c|}
\hline \multirow{2}{*}{$\begin{array}{l}\text { CPAP } \\
\text { Device }\end{array}$} & \multicolumn{3}{|c|}{$5 \mathrm{cmH}_{2} \mathrm{O}$} & \multicolumn{3}{|c|}{$10 \mathrm{cmH}_{2} \mathrm{O}$} & \multicolumn{3}{|c|}{$15 \mathrm{cmH}_{2} \mathrm{O}$} \\
\hline & 1 & 2 & 3 & 1 & 2 & 3 & 1 & 2 & 3 \\
\hline $\begin{array}{l}\text { deltaP } \\
\left(\mathrm{cmH}_{2} \mathrm{O}\right)\end{array}$ & $17.0(1.3)$ & $11.4(0.3)$ & $9.4(0.9)$ & $17.4(1.5)$ & $13.7(1.1)$ & $9.8(0.5)$ & $16.7(1.2)$ & $14.1(1.2)$ & $10.3(0.8)$ \\
\hline $\begin{array}{l}\text { WOBi } \\
(\mathrm{J} / \mathrm{s})\end{array}$ & $3.0(0.30)$ & $2.2(0.12)$ & $1.7(0.25)$ & $3.0(0.35)$ & $2.3(0.22)$ & $1.7(0.08)$ & $2.8(0.21)$ & $2.4(0.30)$ & $1.7(0.19)$ \\
\hline $\begin{array}{l}\text { Rapp } \\
\left(\mathrm{cmH}_{2} \mathrm{O} / 1 / \mathrm{s}\right)\end{array}$ & $3.1(0.21)$ & $2.1(0.08)$ & $1.6(0.12)$ & $3.1(0.27)$ & $2.3(0.14)$ & $1.6(0.16)$ & $2.9(0.14)$ & $2.4(0.23)$ & $1.8(0.09)$ \\
\hline
\end{tabular}

for all figures of performance, except for deltaP for Assembly 3 at $15 \mathrm{cmH}_{2} \mathrm{O}$ and WOBi for Assembly 2 at $15 \mathrm{cmH}_{2} \mathrm{O}$.

Figure 2 shows the Box-whisker-plot of WOBi for all trials. It is evident from this plot that the WOBi was minimal for Assembly 3 for all groups $(\mathrm{p}<0.001$, compared to Assembly 1 and Assembly 2). The other 2 figures of performance, deltaP and Rapp, presented the same pattern.

Figure 3 presents the scatter plot of WOBi versus deltaP (upper panel) and WOBi versus Rapp (lower panel). A high degree of correlation was found, ranging from 0.69 to 0.97 for $\mathrm{WOBi}$ versus deltaP, except for Assembly 2 in Group5B $(r=0.47)$ and from 0.80 to 0.94 for WOBi versus Rapp, with the same exception $(\mathrm{r}=0.45)$.

A high degree of correlation was found between $\mathrm{WOB}_{\mathrm{i}}$ and TI for most of the trials, (median and interquartile range of $(-0.70(0.30))$, whilst the same did not occurs for $\mathrm{WOB}_{\mathrm{i}}$ and TE $(-0.042<\mathrm{r}<0.03)$. Figure 4 shows that $\mathrm{R}_{\text {ins }}$ was higher than $\mathrm{R}_{\exp }$ in all cases. The resistances seen in Mode A were lower than in Mode B, except at $15 \mathrm{cmH}_{2} \mathrm{O}$.

\section{Discussion}

The main results of this study were: in simulated exercise conditions, the WOBi is reduced when the the spring-loaded PEEP valve is fully opened (mode A); there is a high correlation among WOBi, deltaP and Rapp, possibly allowing for an indirect estimation of WOBi by monitoring only deltaP.

The results showed $\mathrm{P}_{\mathrm{ao}}$ swings with amplitudes in the order of magnitude of the CPAP level

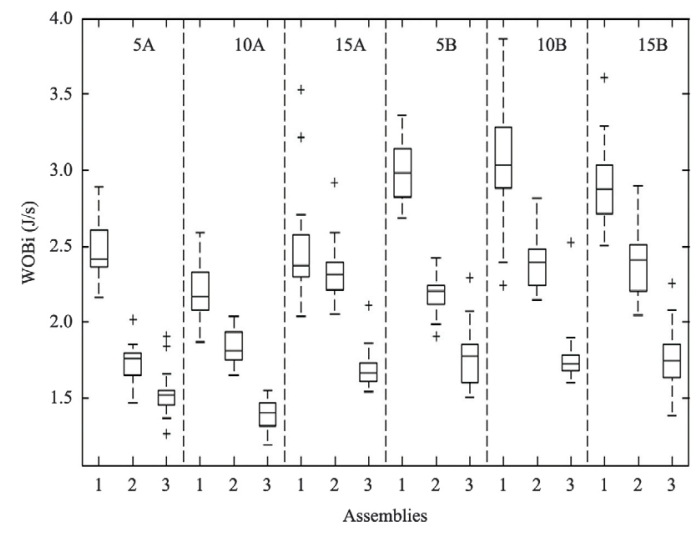

Figure 2. Box-whisker-plot of WOBi for each trial. Assemblies: 1: RemRest; 2: Oxy-PEEP; 3: parallel association of these two models. 05A: CPAP pressure set to $5 \mathrm{cmH}_{2} \mathrm{O}$ with PEEP-valve fully opened; 10A: CPAP pressure set to $10 \mathrm{cmH}_{2} \mathrm{O}$ with PEEP-valve fully opened; 15A: CPAP pressure set to $15 \mathrm{cmH}_{2} \mathrm{O}$ with PEEP-valve fully opened; 5B: CPAP pressure set to $05 \mathrm{cmH}_{2} \mathrm{O}$ with PEEP-valve set to the same value; 10B: CPAP pressure set to $10 \mathrm{cmH}_{2} \mathrm{O}$ with PEEPvalve set to the same value; $15 \mathrm{~B}$ : CPAP pressure set to $15 \mathrm{cmH}_{2} \mathrm{O}$ with PEEP-valve set to the same value.

during exercise simulations and the presence of a subatmospheric inspiratory $\mathrm{P}_{\text {ao }}$ was usual (see Tables 3 and 4). This characteristic must be considered and avoided since it has been reported by Gherini et al. (1979) that the fluctuations of $\mathrm{P}_{\mathrm{ao}}$ impacts directly into WOB.

The assemblies in Mode A presented a reduction in $\mathrm{P}_{\text {ao }}$ swings, possibly due to the decreased springloaded PEEP valve resistance. In fact, according to Banner et al. (1988), the best valves for CPAP applications are the threshold resistor valves with 

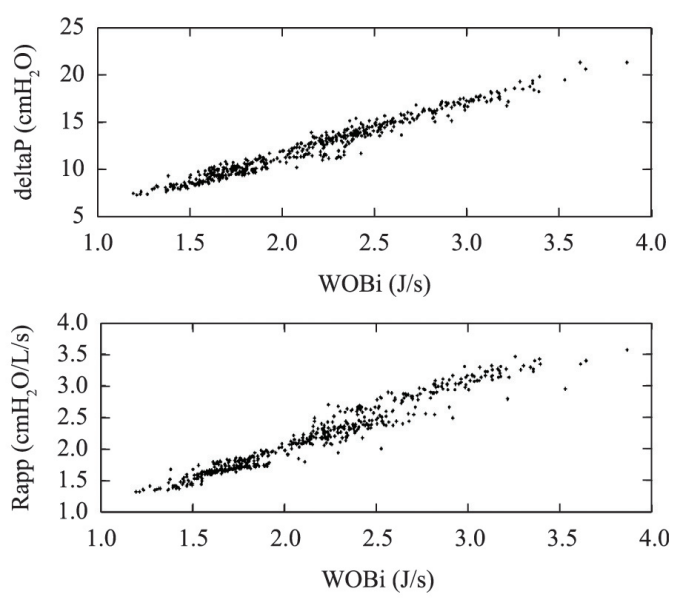

Figure 3. Scatterplot between WOBi and deltaP (Upper panel) or Rapp (Lower panel) for all trials performed by the six groups.
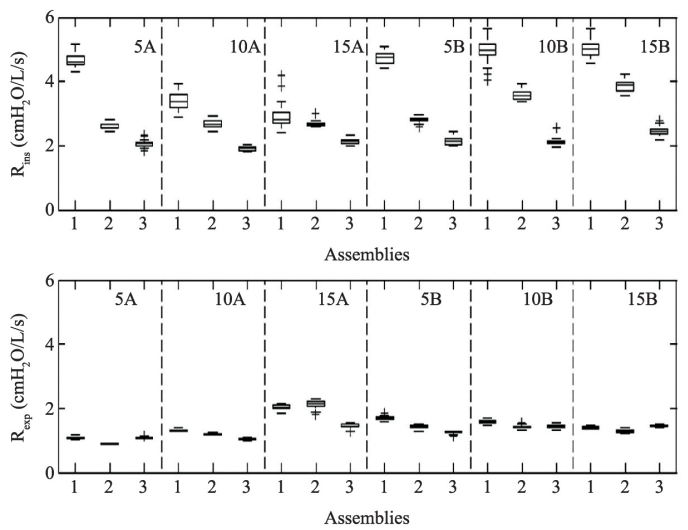

Figure 4. Box-whisker-plot of inspiratory resistance $\left(\mathrm{R}_{\text {ins }}\right)$ (upper) and Expiratory resistance $\left(\mathrm{R}_{\text {exp }}\right)$ (bottom) for each trial. Assemblies: 1 : RemRest; 2: Oxy-PEEP; 3: parallel association of these two models. 05A: CPAP pressure set to $5 \mathrm{cmH}_{2} \mathrm{O}$ with PEEP-valve fully opened; 10A: CPAP pressure set to $10 \mathrm{cmH}_{2} \mathrm{O}$ with PEEP-valve fully opened; 15A: CPAP pressure set to $15 \mathrm{cmH}_{2} \mathrm{O}$ with PEEP-valve fully opened; 05B: CPAP pressure set to $5 \mathrm{cmH}_{2} \mathrm{O}$ with PEEP-valve set to the same value; 10B: CPAP pressure set to $10 \mathrm{cmH}_{2} \mathrm{O}$ with PEEP-valve set to the same value; 15B: CPAP pressure set to $15 \mathrm{cmH}_{2} \mathrm{O}$ with PEEPvalve set to the same value.

low flow resistance. However, Mode A setup may not constitute a general solution since some CPAP generators may not deliver high CPAP pressures with the spring-loaded PEEP valve fully opened. For each assembly considered, the WOBi in Mode A was dependent on the applied CPAP and this effect was less prominent in Mode B.

Katz et al. (1985) described a substantial variation in WOBi dependent on the CPAP device. They examined 8 different CPAP generators at 0,10 and $20 \mathrm{cmH}_{2} \mathrm{O}$ with sinusoidal flow rates set to 20,40 and $60 \mathrm{~L} / \mathrm{min}$ and $\mathrm{V}_{\mathrm{T}}$ of $500 \mathrm{~mL}$. In the presence of delivered gas flow rates higher than the patient's inspiratory flow rate, the circuit resistance during inspiration was negligible. They also described that the clinical implications for the wide WOBi changes, seen in different CPAP systems, may be relevant only for patients with compromised respiratory mechanics or high inspiratory flow demand. Indeed, the Assembly 3 , consisting in the parallel association of two devices, presented the minimal $R_{\text {ins }}$ (see Figure 4). Since the present protocol fixed the ventilatory demand in all cases, possibly the Assembly 2 in Mode A had a reduction in delivered gas flowat increased CPAP levels (see WOBi changes in Figure 2).

The WOBi ranged roughly from 25 to $50 \%$ of the magnitude of corresponding physiologic WOB, as reported by Guenette and Sheel (2007) for normal subjects at $70 \%$ of $\mathrm{VO}_{2 \text { max }}$. This suggests that the burden of the CPAP device may represent a large portion of the total WOB.

Taking into account that $\mathrm{V}_{\mathrm{T}}$ was fixed in the present study, the cycle-by-cycle variations of TI or TE changed the corresponding mean flow rate. Changes in inspiratory flow demand, related to TI, could have led variations in $\mathrm{R}_{\text {ins }}$, whereas changes in $\mathrm{TE}$ did not produce equivalent variations in $\mathrm{R}_{\text {exp }}$ (see Figure 4). In our experimental setup, the variations in deltaP, Rapp and WOBi presented a significant correlation with TI, not with TE, possibly because $\mathrm{R}_{\text {ins }}$ was greater than $\mathrm{R}_{\exp }$ in all cases, and due to the large variation of $\mathrm{R}_{\text {ins }}$, as mentioned previously.

The strong degree of correlation among WOBi, Rapp and deltaP may allow the use of deltaP as an estimator of WOBi. The continuous acquisition of the deltaP signal is straightforward and the beginning of inspirations and expirations may be identified by the intercept of the pressure signal with the CPAP present for zero flow rate condition, available with a pause maneuver.

It is important to comment that many studies employing prescribed CPAP in exercise protocols did not refer to the measurement of $\mathrm{P}_{\text {ao }}$ (Keilty et al., 1994; Wittmer et al. 2006), and the level and stability of the applied CPAP may rest unknown. On the other side, the work of Petrof et al. (1990) reported the range of the swings of the applied CPAP, certainly a more realistic and quantitative description of the procedure. As seen in this study and in the literature, the $\mathrm{P}_{\mathrm{ac}}$ swings are directly related to the CPAP device system as well as to the demand of the subject. Thus, comparisons of functional or clinical CPAP prescriptions must consider the actual conditions of use and it is not appropriate and sufficient to report only the ideal CPAP level.

An alternative solution to decrease the Pao swings, described by Favre et al. (2003), is a closed-loop control of Pao by employing a proportional valve regulating the flow rate demand. 
Some sources of uncertainty of the present study, like the calibration performed in absence of a positive pressure, the changes in $\mathrm{V}_{\mathrm{T}}, \mathrm{TI}$ and TE resulting from the manual strokes of the syringe and the method to estimate $\mathrm{P}_{\text {adiust }}$, do not seem to invalidate the main findings of the present work; nevertheless, they may be evaluated in further studies, for instance by using an automated syringe.

In conclusion, as expected, Assembly 3 presented the best performance in terms of WOBi and deltaP. Mode A (spring-loaded PEEP valve fully opened) showed better performance than Mode B (springloaded valve adjusted for the desired pressure) for all assemblies. The quantification of CPAP swings may be useful to estimate the WOBi. In vivo studies are required to confirm the present results.

\section{Acknowledgements}

Authors wish to thank the technician Luciano T. Kagami for the support in this study. CNPq, CAPES and FAPERJ provided partial financial support.

\section{References}

Ambrosino N, Strambi S. New strategies to improve exercise tolerance in chronic obstructive pulmonary disease. European Respiratory Journal. 2004; 24(2):313-22. http://dx.doi.org/ $10.1183 / 09031936.04 .00002904$

Banner MJ, Downs JB, Kirby RR, Smith RA, Boysen PG, Lampotang S. Effects of expiratory flow resistance on inspiratory work of breathing. Chest. 1988; 93(4):795-9. PMid:3280260. http://dx.doi.org/10.1378/chest.93.4.795

Banner MJ, Kirby RR, Blanch PB. Differentiating total work of breathing into its component parts: Essential for appropriate interpretation. Chest. 1996; 109(5):1141-3. PMid:8625657. http://dx.doi.org/10.1378/chest.109.5.1141

Favre AS, Jandre FC, Giannella-Neto A. Closed-Loop Control of a Continuous Positive Airway Pressure Device.In: Annual International Conference of the IEEE Engineering in Medicine and Biology Society: Proceedings of the 25th Annual International Conference of the IEEE Engineering in Medicine and Biology Society; 2003; Cancun. IEEE Engineering in Medicine and Biology Society; 2003. p. 141. PMid:12767802. http://dx.doi.org/10.1109/IEMBS.2003.1279696

Gherini S, Peters RM, Virgilio RW. Mechanical work on the lungs and work of breathing with positive endexpiratory pressure and continuous positive airway pressure.
Chest. 1979; 76(3):251-6. http://dx.doi.org/10.1378/ chest.76.3.251

Giannella-Neto A, Bellido C, Barbosa RB, Vidal Melo MF. Design and calibration of unicapillary pneumotachographs. Journal of Applied Physiology. 1998; 81(1):335-43.

Guenette JA, Sheel AW. Physiological consequences of a high work of breathing during heavy exercise in humans. Journal of Science and Medicine in Sport; 2007; 10(6):34150. PMid:17418638. http://dx.doi.org/10.1016/j. jsams.2007.02.003

Haverkamp HC, Dempsey JA, Miller JD, Romer LM, Eldridge MW. Physiologic basis of respiratory disease. Hamilton: PMPH USA; 2005.

Katz JA, Kraemer RW, Gjerde GE. Inspiratory work and airway pressure with continuous positive airway pressure delivery systems. Chest. 1985; 88(4):519-26. PMid:3899530. http://dx.doi.org/10.1378/chest.88.4.519

Keilty SEJ, Ponte J, Fleming TA, Moxham J. Effect of inspiratory pressure support on exercise tolerance and breathlessness in patients with severe stable chronic obstructive pulmonary disease. Thorax; 1994; 49(10):9904. PMid:7974316 PMCid:PMC475234. http://dx.doi. org/10.1136/thx.49.10.990

Louis B, Leroux K, Boucherie M, Isabey D, Grillier-Lanoir V, Fauroux B, Lofaso F. Pressure stability with CPAP devices: A bench evaluation. Sleep Medicine. 2010; 11(1):969. PMid:19892594. http://dx.doi.org/10.1016/j. sleep.2009.02.011

Petrof BJ, Calderini E, Gotfried SB. Effect of CPAP on respiratory effort and dyspnea in severe COPD. Journal of Applied Physiology. 1990; 69(1):179-88. PMid:2203722.

Pino AV, Kagami LT, Jandre FC, Giannella-Neto A. DAS - Um programa de aquisição e processamento de sinais para engenharia pulmonar. In: Congresso Latino Americano de Engenharia Biomédica: Anais do III Congresso Latino Americano de Engenharia Biomédica, 2004, João Pessoa. João Pessoa: SBEB, CORAL, IFMBE; 2004a. v. 5, p. 765-8.

Pino AV, Carvalho AR, Lima F, Bozza FA, Salluh J, Ascoli F, Soares JHN, Jandre FC, Giannella-Neto A. Controle automático da ventilação mecânica para minimizar a lesão pulmonar induzida pela ventilação. Revista Brasileira de Engenharia Biomédica. 2004b; 20(2-3):89-95.

Wittmer VL, Simoes GM, Sogame LC, Vasquez EC. Effects of continuous positive airway pressure on pulmonary function and exercise tolerance in patients with congestive heart failure. Chest. 2006; 130(1):157-63. PMid:16840396. http://dx.doi.org/10.1378/chest.130.1.157

\footnotetext{
Authors

Marcelo Vieira Leão Nunes", Antonio Giannella-Neto, Frederico Caetano Jandre de Assis Tavares

Pulmonary Engineering Laboratory, Biomedical Engineering Program, Alberto Luiz Coimbra Institute for Graduate

Studies and Research in Engineering - COPPE, Federal University of Rio de Janeiro - UFRJ, Av. Horácio Macedo 2030,

Prédio do Centro de Tecnologia, Bloco H, Sala 327, Cidade Universitária, CEP 21941-914, Rio de Janeiro, RJ, Brazil
} 